02

\title{
Комбинационное рассеяние света в кремнии с нарушенной кристаллической структурой за счет имплантации ионов углерода
}

\author{
(C) A.B. Иго \\ Ульяновский государственный университет, \\ 432063 Ульяновск, Россия \\ e-mail: igoalexander@mail.ru
}

Поступила в редакцию 26.02.2020 г.

В окончательной редакции 02.04.2020 г.

Принята к публикации 24.04.2020 г.

\begin{abstract}
Зарегистрированы спектры комбинационного рассеяния света в кремнии с нарушенной кристаллической решеткой за счет имплантации ионов углерода энергией $40 \mathrm{keV}$ и дозой $5 \cdot 10^{16} \mathrm{~cm}^{-2}$. Измерены параметры спектральной линии комбинационного рассеяния света имплантированных образцов после проведения термического отжига в диапазоне температур $600-1150^{\circ} \mathrm{C}$. В результате измерений определена доля кристаллической фазы в зависимости от температуры отжига. Выявлены два термодинамических процесса, описывающие кинетику восстановления кристаллической решетки при отжиге. Показано, что слой кремния с нарушенной кристаллической решеткой при термическом отжиге восстанавливает свою кристалличность не одновременно во всем объеме, а в виде кластеров, которые с увеличением температуры отжига укрупняются. Проведены оценки размеров кристаллических кластеров для различных температур отжига. Проведенные расчеты учитывают сложную зависимость коэффициента поглощения света частично нарушенной кристаллической решетки от доли кристаллической фазы, возникающей в ней в процессе термического отжига.
\end{abstract}

Ключевые слова: комбинационное рассеяние света, кремний, нанокристаллы, ионная имплантация, отжиг, аморфная фаза.

DOI: $10.21883 /$ OS.2020.08.49707.70-20

\section{Введение}

Имплантация ионов в монокристаллический слой кремния является важной технологической операцией современной электронной промышленности. Технология подробно изучена в общем случае [1] и в частном случае ионов углерода в монокристаллический слой кремния [2,3]. Технология позволяет создавать структуры с заданным профилем концентрации внедряемых ионов. Внедрение ионов в больших дозах $\left(5 \cdot 10^{17} \mathrm{~cm}^{-2}\right)$ и последующий высокотемпературный отжиг структур $\left(1200^{\circ} \mathrm{C}\right)$ позволили создать области карбида кремния (SiC) в кремнии, что подтверждено экспериментально методами дифракции рентгеновских лучей (XRD), инфракрасной спектроскопии [2], просвечивающей электронной микроскопии [3].

Ионная имплантация значительных доз примеси приводит к полной аморфизации кристаллического слоя на всю глубину проникновения ионов [1]. Экспериментально это подтверждено методами XRD и комбинационного рассеяния света (КРС) [4]. Важной составляющей технологии является температурная обработка (отжиг) структуры, во время которой в ней происходит восстановление кристалличности слоя кремния. В [1] обобщены исследования отжига структурных дефектов решетки кремния по данным XRD. Собственно отжиг это самостоятельная важная операция в электронной промышленности, технологические исследования которой продолжаются, в частности, для создания кристал- лических слоев кремния из аморфных слоев кремния, полученных методом осаждения из газовой фазы $[5,6]$. Проведенные исследования показали, что в результате воздействия температуры в течение длительного промежутка времени или в виде краткого импульса аморфная фаза кремния переходит в кристаллическое состояние. Целью настоящей работы является изучение кинетики образования кристаллической фазы из нарушенной кристаллической (аморфной) и измерение доли кристаллической фазы в зависимости от параметров отжига методом КРС.

Исследования отжига аморфизированных слоев показывают, что образование кристаллической фазы происходит в виде процесса возникновения и роста кластеров кристаллической фазы [5,6]. Спектроскопия КРС позволяет регистрировать возникновение кристаллической фазы из аморфной, а по интенсивности спектральной линии судить о ее количестве. Зарождающиеся кристаллиты окружены аморфным кремнием, коэффициент поглощения света которого для видимого диапазона значительно (на порядок) выше, чем в монокристаллической фазе. Целью настоящей работы является установление связи между интенсивностью спектральной линии КРС и объемной долей кристаллической фазы в образцах при разных температурах отжига.

Спектроскопия КРС является чувствительным методом определения размеров частиц и кластеров в диапазоне размеров $1-20 \mathrm{~nm}$ за счет эффекта пространственного ограничения оптических фононов. Для нано- 
кристаллов кремния известна связь между их размером, смещением спектральной линии КРС и увеличением ее спектральной ширины [7,8]. Целью настоящей работы является определение размера кластеров для разных температур отжига образцов методом КРС, учитывая, что образующиеся нанокристаллы окружены аморфным кремнием.

\section{Экспериментальные образцы и методика измерений}

В работе исследованы две пластины монокристаллического кремния с ориентацией (100), с одной стороны которых проведена имплантация ионов углерода $\left(\mathrm{C}^{+}\right)$ дозой $5 \cdot 10^{16} \mathrm{~cm}^{-2}$, отличающиеся энергией частиц: образец 1 - энергия частиц $E=10 \mathrm{keV}$, образец 2 $E=40 \mathrm{keV}$. Обратная сторона пластины в измерениях использовалась как референтный монокристаллический кремний.

Измерение спектров КРС проводилось на модернизированном спектрометре ДФС-52 с ФЭУ Н6240-01. Для возбуждения КРС использовался лазер с длиной волны $532 \mathrm{~nm}$ и мощностью $25 \mathrm{~mW}$. Рассеянный свет регистрировался в геометрии обратного рассеяния. Ширина входной щели монохроматора составляла $0.4 \mathrm{~mm}$. Зарегистрированные спектры анализировались с помощью программы Origin 8 для определения параметров спектральной линии. Интенсивность спектральной линии определялась как площадь под спектральной линией, аппроксимированной контуром Фойгта. Ширина спектральной линии определялась, как лоренцева составляющая Г спектрального контура Фойгта с фиксированной гауссовой составляющей $\Gamma_{g}$, равной $3.1 \mathrm{~cm}^{-1}$, которая является инструментальной спектральной шириной монохроматора ДФС-52 с щелью $0.4 \mathrm{~mm}$. Значение инструментальной спектральной ширины монохроматора получено экспериментально по измерению материалов с известными ширинами спектральных линий. В частности, при использовании $\Gamma_{g}=3.1 \mathrm{~cm}^{-1}$ спектральная ширина линии монокристаллического кремния $\Gamma$ составляет $3.4 \mathrm{~cm}^{-1}$. Такая методика измерений (широкая щель $0.4 \mathrm{~mm}$ ) является вынужденной, так как интенсивность сигнала от имплантированных и нарушенных слоев кремния является низкой, а использование более мощного лазера может приводить к локальному нагреву образца и как результат к неправильному значению ширины спектральной линии.

Исследования кинетики образования кристаллической фазы в аморфизированном слое проводились в образце 2 $(E=40 \mathrm{keV})$. Имплантированная пластина была разрезана на несколько образцов размера $5 \times 5 \mathrm{~mm}$, каждый из которых отжигался в муфельной печи при определенной температуре в течение $1 \mathrm{~h}$. Диапазон температур отжига $600-1150^{\circ} \mathrm{C}$.

\section{Измерение интенсивности КРС в имплантированных образцах}

В таблице представлены результаты измерения спектров КРС в образцах 1 и 2 и референтном монокристалле. Полученные результаты могут быть использованы для оценки коэффициента поглощения нарушенного слоя кремния.

Интенсивность КРС в поглощающей среде может быть рассчитана на основании закона Бугера, как показано на рис. 1. В частности, для монокристалла интенсивность рассеянного света в геометрии обратного рассеяния выражается через интенсивность падающего света, компоненту тензора КРС кремния $R$, площадь светового пятна $s$ и коэффициент поглощения в монокристалле кремния $\alpha$ :

$$
I_{s}^{0}=s I^{0} R \int_{0}^{\infty} e^{-2 a x} d x=\frac{s I^{0} R}{2 \alpha}
$$

Глубина проникновения света $532 \mathrm{~nm}$ в кремний порядка $1 / \alpha=1 / 11.2 \cdot 10^{3} \mathrm{~cm}^{-1} \approx 900 \mathrm{~nm}$, что значительно больше, чем оценки толщины нарушенного слоя по данным параметров распределения. Так как дозы имплантации значительны, в качестве оценки толщины нарушенного слоя можно взять $d=R_{0}+3 \Delta R_{0}$. Расчеты $d$ для образцов представлены в таблице.

Положение максимума и ширина спектральной линии КРС образца 1 свидетельствуют, что был зарегистрирован спектр ненарушенного слоя кремния, а меньшее значение интенсивности может быть связано с тем, что нарушенный слой сверху поглотил часть излучения. Больший коэффициент поглощения света аморфного кремния для $532 \mathrm{~nm}$ по сравнению с монокристаллическим кремнием связан с наличием хвостов плотности состояний в запрещенной зоне [9] и существенно зависит от технологии получения аморфного кремния [6,9]. По разным данным коэффициент поглощения аморфного кремния $k$ для $532 \mathrm{~nm}$ в 10-25 раз больше, чем $\alpha$ в монокристалле. Используя значение интенсивности КРС образца 1 и учитывая, что перед кристаллическим слоем свет частично поглощается, как показано на рис. 1,
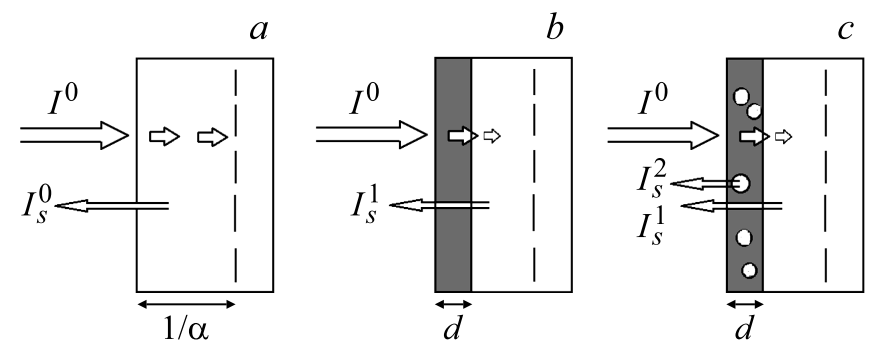

Рис. 1. Интенсивность спектров КРС: монокристалла $(a)$, монокристалла с нарушенным слоем $(b)$, монокристалла с нарушенным слоем, в котором присутствуют нанокристаллы $(c)$. 
Таблица

\begin{tabular}{c|c|c|c|c|c|c|c|c}
\hline \multirow{2}{*}{ Образец } & $\begin{array}{c}\text { Энергия, } \\
\mathrm{keV}\end{array}$ & \multicolumn{2}{|c|}{$\begin{array}{c}\text { Параметры } \\
\text { распределения [2] }\end{array}$} & $\begin{array}{c}\text { Интенсивность, } \\
\text { arb. units }\end{array}$ & $\begin{array}{c}\text { Положение } \\
\text { максимума, } \\
\mathrm{cm}^{-1}\end{array}$ & $\begin{array}{c}\text { Ширина } \\
\text { спектральной } \\
\text { линии, } \mathrm{cm}^{-1}\end{array}$ & $\begin{array}{c}\text { Толщина } \\
\text { аморфного } \\
\text { слоя, } d, \mathrm{~nm}\end{array}$ & $\begin{array}{c}\text { Расчет } \\
\text { коэффициента } \\
\text { поглощения, } \\
10^{4} \mathrm{~cm}^{-1}\end{array}$ \\
\hline моно & - & - & - & 9256 & 520 & 3.4 & - & - \\
1 & 10 & 24 & 13 & 638 & 520 & 3.4 & 63 \\
2 & 40 & 93 & 34 & 0 & - & - & 21 \\
\end{tabular}

получим

$$
I_{s}^{1}=s I^{0} e^{-2 k d} R \int_{0}^{\infty} e^{-2 \alpha x} d x=\frac{s I^{0} e^{-2 k d} R}{2 \alpha}=I_{s}^{0} e^{-2 k d} .
$$

Здесь для простоты не учитываем отражение света на границе раздела сред, считая, что аморфизация слоя оказывает не слишком большое влияние на показатель преломления [9]. Используя экспериментальные значения интенсивностей и расчетные значения толщины нарушенного слоя для двух образцов (таблица), получим значение коэффициента поглощения нарушенного слоя $k=21 \cdot 10^{4} \mathrm{~cm}^{-1}$. Он оказался одинаковым для двух образцов и согласуется с диапазоном данных [9] для аморфного кремния.

\section{Измерение спектров КРС в отожженных образцах имплантированного кремния}

Измерение спектров КРС было проведено в образцах имплантированного кремния с энергией $E=40 \mathrm{keV}$ после проведенного отжига при температурах 600, 650, $680,700,725,750,770,800,820,870,900,930,970,1100$, $1150^{\circ} \mathrm{C}$. Спектры образцов без отжига и отожженных при температурах 680, $770^{\circ} \mathrm{C}$ представлены на рис. 2. Спектр КРС образца без отжига представляет собой широкий максимум в области $480 \mathrm{~cm}^{-1}$ аморфного кремния, а спектры образцов после отжига имеют спектральные линии КРС кристаллической фазы кремния $520 \mathrm{~cm}^{-1}$. Зависимость интенсивности спектральной линии КРС кристаллической фазы от температуры отжига представлена на рис. 3.

Интенсивность спектральной линии КРС образца, отожженного при температурах 1100 и $1150^{\circ} \mathrm{C}$ составляла 0.85 от интенсивности монокристаллического кремния, а ширина спектральной линии составляла $3.7 \mathrm{~cm}^{-1}$. Снижение интенсивности линии КРС и увеличение ширины также может быть связано с присутствием имплантированных ионов углерода в доле порядка 1:100. После отжига при таких температурах примеси распределены в междоузлиях, тем не менее они создают искажение кристаллической решетки. По измерениям [10] в подобных образцах и условиях отжига внутренние напряжения в кристаллической решетке составляют порядка $5 \cdot 10^{8} \mathrm{~Pa}$

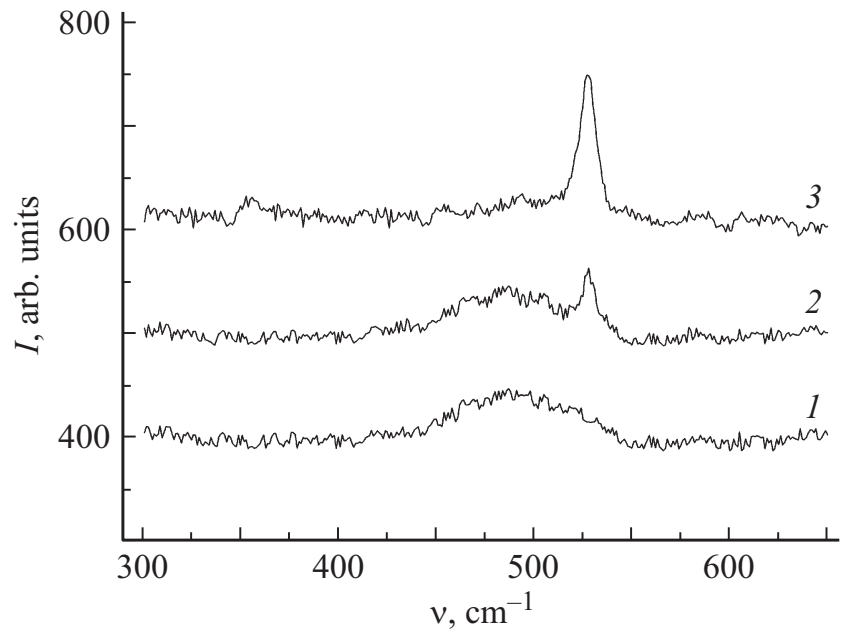

Рис. 2. Спектры КРС образцов имплантированного кремния: 1 - без термического отжига, $2-$ отжиг $1 \mathrm{~h}$ при $T=680^{\circ} \mathrm{C}$, 3 - отжиг $1 \mathrm{~h}$ при $T=770^{\circ} \mathrm{C}$.

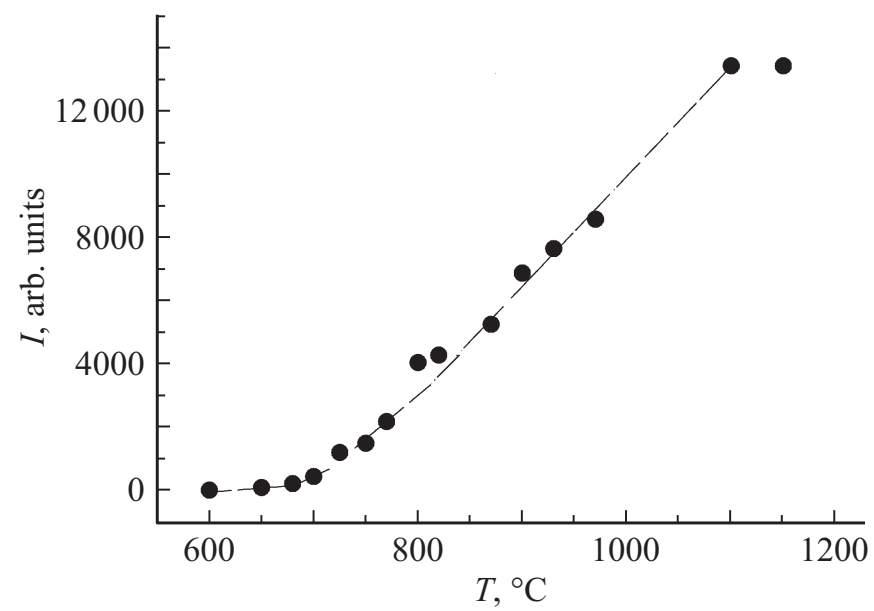

Рис. 3. Зависимость интенсивности линии КРС кристаллической фазы от температуры отжига.

и распределены неравномерно, что может приводить к сдвигу и уширению спектральной линии до $2 \mathrm{~cm}^{-1}$. В нашем случае наблюдается уширение на $0.3 \mathrm{~cm}^{-1}$.

Интенсивность спектральной линии кристаллической фазы пропорциональна объемной доле кристаллической фазы в аморфизированном (нарушенном) слое. Допол- 


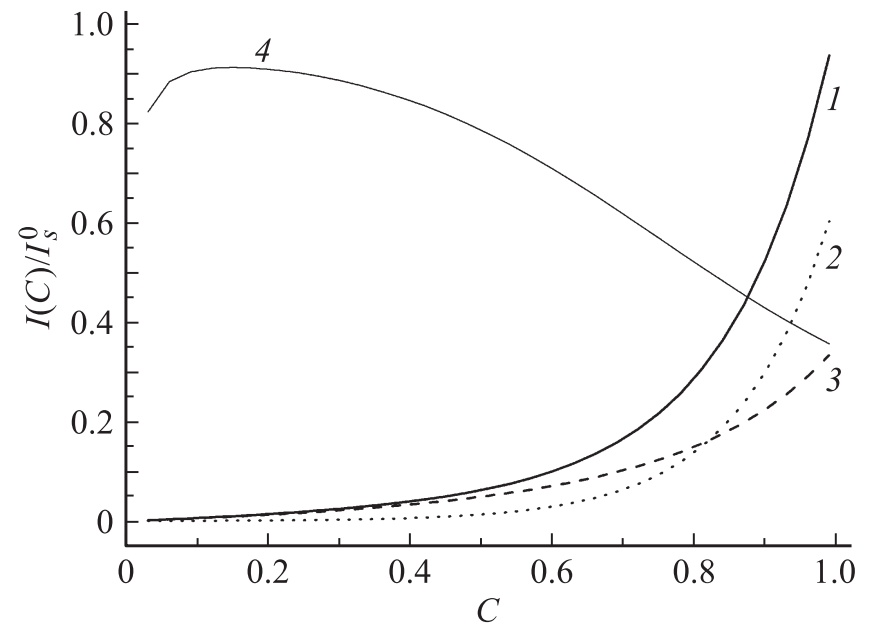

Рис. 4. Расчетная зависимость интенсивности линий КРС от концентрации кристаллической фазы: в нарушенном слое (3), от монокристаллической области за нарушенным слоем (2), их сумма (1). Доля интенсивности линий КРС кристаллической фазы в нарушенном слое от общей интенсивности КРС (4).

нительно появление кристаллической фазы объемной доли С приводит к уменьшению поглощения в нарушенном слое (концентрационный закон Бугера-Ламберта-Бера), что приводит к увеличению интенсивности линий КРС из монокристаллической области за нарушенным слоем. Пусть результирующий коэффициент поглощения смеси двух фаз

$$
\delta=\alpha C+k(1-C) .
$$

Тогда суммарная интенсивность линий КРС от двух областей, как показано на рис. 1, будет

$$
\begin{aligned}
I(C)= & C s I^{0} R \int_{0}^{d} e^{-2 \delta x} d x+I_{s}^{0} e^{-2 \delta d} \\
& =I_{s}^{0}\left(C \frac{\alpha}{\delta}\left(1-e^{-2 \delta d}\right)+e^{-2 \delta d}\right) .
\end{aligned}
$$

Полученное уравнение можно использовать для определения объемной доли кристаллической фазы $C$ в нарушенном слое по измеренной интенсивности спектральной линии КРС $\left(520 \mathrm{~cm}^{-1}\right)$ в эксперименте. График зависимости двух слагаемых интенсивности и их суммы от $C$ приведен на рис. 4.

Используя экспериментальные значения интенсивности линий КРС образца для разных температур отжига (рис. 3) и полученную зависимость $I(C)$, рассчитаем зависимость $C$ от температуры отжига. На рис. 5 представлена зависимость логарифма объемной доли кристаллической фазы от обратной абсолютной температуры отжига. Судя по графику, эта зависимость имеет явный активационный вид типа

$$
C=C_{0} \exp \left(-\frac{E_{1}}{k T}\right)
$$

с энергией активации $E_{1}=0.8 \mathrm{eV}$ в области $600-800^{\circ} \mathrm{C}$ и $E_{1}=0.09 \mathrm{eV}$ в области $800-1100^{\circ} \mathrm{C}$. Первый термодинамический процесс упорядочения кристаллической решетки похоже связан с возвратом атомов кремния из смещенных метастабильных положений в узлы решетки. Воздействие легких ионов $\mathrm{C}^{+}$с невысокими энергиями внедрения незначительно смещает ионы кристаллической решетки имплантируемого образца [1]. Эта расстояние можно оценить по диффузионной длине для заданной температуры и времени $\tau$ отжига $L=\sqrt{\tau D}$. Коэффициент самодиффузии кремния [11]

$$
D=D_{0} \exp \left(-\frac{E_{2}}{k T}\right),
$$

$D_{0}=530 \mathrm{~cm}^{2} / \mathrm{c}, E_{2}=4.75 \mathrm{eV}$. На рис. 5 штриховой линией приведен расчет $L$ для температур отжига образцов (правая ось ординат). При отжиге $1 \mathrm{~h}$ при $750^{\circ} \mathrm{C}$ диффузионная длина становится равна $0.02 \mathrm{~nm}$. При этом доля восстановленной кристаллической фазы составляет $60 \%$, т. е. большая часть атомов кремния была смещена от равновесного положения менее чем на $0.02 \mathrm{~nm}$.

Поглощение света в аморфизированном слое связано со степенью разупорядочения этого слоя $[9,12]$. По аналогии с кристаллическим кремнием спектральную зависимость коэффициента поглощения аморфного кремния записывают в виде

$$
k=\frac{B^{2}}{\hbar \omega}\left(\hbar \omega-E_{g}\right)^{2},
$$

где $B=700 \mathrm{~cm}^{-1 / 2} \mathrm{eV}^{-1}$ - эмпирический коэффициент, a $E_{g}$ - усредненная оптическая ширина запрещенной зоны аморфного кремния. Распределение значений $E_{g}$ по некоторой области кристалла обычно считают гауссовым, а дисперсия этого распределения $E_{0}$ является вторым важным параметром, определяющим оптические свойства аморфного кремния. Эта величина проявляет

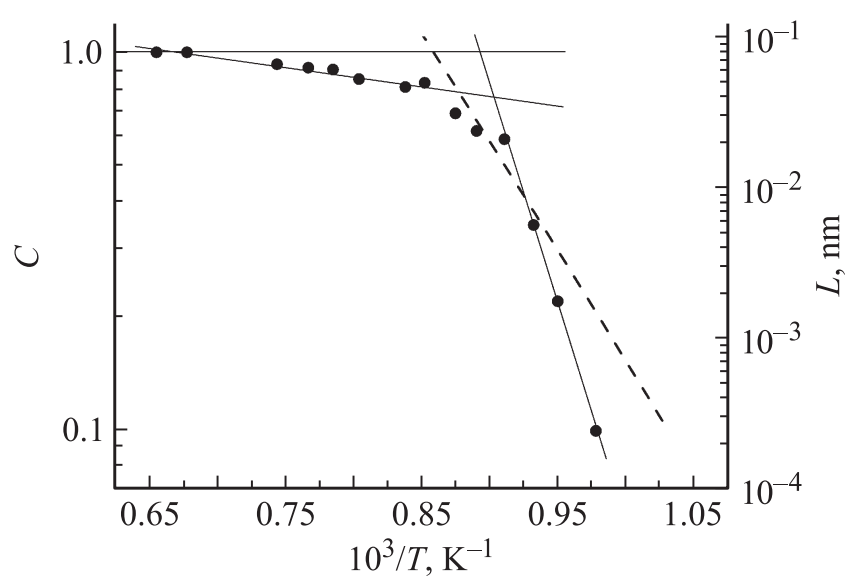

Рис. 5. Зависимость логарифма объемной доли кристаллической фазы от обратной абсолютной температуры отжига образца. Штриховой линией показана температурная зависимость диффузионной длины (правая ось). 
себя в сдвиге края собственного поглощения согласно правилу Урбаха:

$$
k=\alpha \exp \left(\frac{\hbar \omega-E_{g}}{E_{0}}\right) .
$$

Дисперсия распределения ширины запрещенной зоны аморфного кремния прямо связана с дисперсией распределения отклонений атомов от их положений в узлах кристаллической решетки $\left\langle U^{2}\right\rangle$ и может быть оценена [12] по формуле

$$
E_{0}=\frac{3 \theta_{D}}{4} \frac{\left\langle U^{2}\right\rangle}{\left\langle U_{0}^{2}\right\rangle}
$$

где $\theta_{D}=0.054 \mathrm{eV}$ - температура Дебая, $\left\langle U_{0}^{2}\right\rangle-$ среднеквадратическое тепловое отклонение узловых атомов решетки. При нормальных условиях $\sqrt{\left\langle U_{0}^{2}\right\rangle}=0.008 \mathrm{~nm}$.

Используя полученный в эксперименте коэффициент поглощения аморфного кремния (таблица) для $532 \mathrm{~nm}$, получим $E_{g}=1.31 \mathrm{eV}, E_{0}=0.33 \mathrm{eV}, \sqrt{\left\langle U^{2}\right\rangle}=0.02 \mathrm{~nm}$, что согласуется с оценками разупорядочения по длине диффузии.

Изменение наклона зависимости $C(T)$ для $C>0.6$ возможно связано с негауссовым распределением отклонений атомов кремния от равновесных положений под воздействием имплантации. Значительные смещения отдельных атомов приводят к ситуации, когда кристаллическая фаза возникает не равномерно во всем объеме, а в виде кластеров, которые с увеличением температуры отжига укрупняются. Возникновение кристаллической фазы в виде кластеров в эксперименте наблюдалось по регистрации увеличенной ширины спектральной линии кристаллической фазы кремния в области температур отжига от 700 до $1100^{\circ} \mathrm{C}$. Результаты измерений представлены на рис. 6 , кривая 1 .

Согласно модели (1), интенсивность линии КРС представляет собой сумму двух компонент. Для изучения наличия кластеров и определения их размера в нарушенном слое кремния в расчетах необходимо исключить влияние излучения КРС от области с кристаллическим кремнием. При температурах отжига $600-700^{\circ} \mathrm{C}$ кристаллическая фаза в спектре наблюдается (рис. 2), но ее наличие связано не с появлением кластеров, а только лишь с уменьшением коэффициента поглощения $\delta$ в (1) за счет уменьшения разупорядочения.

Наблюдаемая в эксперименте спектральная линия интенсивности $I_{0}$ с шириной $\Gamma$ и положением максимума $v_{0}$, является суммой двух спектральных линий:

$$
\begin{aligned}
I_{0} \frac{(\Gamma / 2)^{2}}{\left(v-v_{0}\right)^{2}+(\Gamma / 2)^{2}}= & I_{1} \frac{\left(\Gamma_{1} / 2\right)^{2}}{\left(v-v_{01}\right)^{2}+\left(\Gamma_{1} / 2\right)^{2}} \\
& +I_{2} \frac{\left(\Gamma_{2}\right)^{2}}{\left(v-v_{02}\right)^{2}+\left(\Gamma_{2}\right)^{2}} .
\end{aligned}
$$

Первая линия интенсивностью $I_{1}$ является спектральной линией излучения монокристаллического кремния

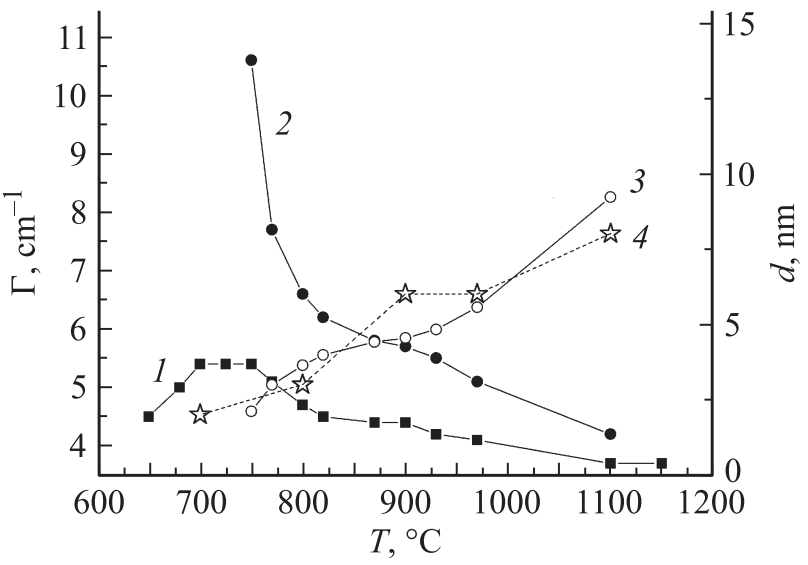

Рис. 6. Зависимость ширины спектральной линии КРС образцов от температуры отжига (1), ширина спектральной линии КРС от кластеров в нарушенном слое (2). Расчет среднего размера кристаллического кластера (3). Расчет среднего размера кластера методом XRD из [2] (4).

из-под нарушенного слоя, имеет ширину $\Gamma_{1}=3.4 \mathrm{~cm}^{-1}$ и $v_{01}=520 \mathrm{~cm}^{-1}$. Вторая линия $I_{2}-$ это спектральная линия от кластеров кристаллического кремния, имеет ширину $\Gamma_{2}$ и положение максимума $v_{02}$. Отношение интегральных интенсивностей двух спектральных линий, согласно модели (1), представлено на рис. 3 в виде кривой 4. Используя эти данные, с помощью программы Origin 8 численным моделированием проведен расчет значений $\Gamma_{2}$. Результаты расчета приведены на рис. 6 , кривая 2.

Большая ширина спектральной линии КРС кластера связана с его малым размером за счет пространственного ограничения оптических фононов, подробно исследованного в кремнии $[5,7,13]$. Накопленные экспериментальные результаты $[13,14]$ и модельные представления [15] позволяют использовать эмпирическое соотношение [13] между дополнительной шириной спектральной линии $\Delta \Gamma$ и размером кластера $d$ :

$$
\Delta \Gamma=\frac{A}{d^{1.5}} .
$$

Используя значения $\Delta \Gamma=\left(\Gamma_{2}-3.4\right) \mathrm{cm}^{-1}$ и $A=22$, pacсчитаем зависимость размера кристаллического кластера от температуры отжига образца. Расчет представлен на рис. 6 кривой 3 (правая ось). Для сравнения на рисунке звездочками (кривая 4) представлены измерения среднего размера кристаллических кластеров в похожих образцах методом XRD из работы [2]. Размеры кластеров в зависимости от температуры отжига лежат в области $2-20 \mathrm{~nm}$, что согласуется с результатами большинства исследователей.

Отжиг при температурах $650-750^{\circ} \mathrm{C}$ приводит к появлению спектра КРС кристаллической фазы (рис. 2). Измерение ширины спектральной линии (рис. 6) свидетельствует, что это КРС в значительной степени от монокристаллического кремния, расположенного под 
нарушенным слоем. Модель (1) этого не учитывает. В этой области (области малых объемных долей $C$ ) расчет предсказывает преобладание интенсивности КРС от нанокристаллов нарушенного слоя с коэффициентом 0.8-0.9 (рис. 4). При выводе формулы (1) не учитывалось, что интенсивность КРС зависит от размера нанокристаллов, образующих рассеивающий объем. Такая зависимость исследована [16] и может быть использована для доработки модели. Вторым возможным фактором является сложная зависимость коэффициента поглощения аморфной фазы k от температуры отжига.

\section{Выводы}

Зарегистрированы спектры КРС в кремнии в образцах с кристаллической решеткой, нарушенной за счет имплантации атомов углерода, до и после проведения термического отжига в диапазоне температур $600-1150^{\circ} \mathrm{C}$. В результате измерений интенсивности и ширины спектральной линии КРС кристаллической фазы кремния определена доля кристаллической фазы в зависимости от температуры отжига.

Выявлено, что образование кристаллической фазы в нарушенном слое подчиняется активационному закону, определены два термодинамических процесса, описывающих кинетику восстановления кристаллической решетки при отжиге.

Проведены оценки коэффициента поглощения и величины разупорядочения в нарушенном слое кремния. Показано, что слой кремния с нарушенной кристаллической решеткой при термическом отжиге восстанавливает свою кристалличность не одновременно во всем объеме, а в виде кластеров, которые с увеличением температуры отжига укрупняются. Использована математическая модель, учитывающая, что кристаллические кластеры окружены аморфной средой с большим коэффициентом поглощения. Проведены оценки размеров кристаллических кластеров для различных температур отжига.

\section{Благодарности}

Автор благодарит Р.И. Баталова за предоставленные для исследования образцы имплантированного кремния.

\section{Конфликт интересов}

Авторы заявляют, что у них нет конфликта интересов.

\section{Список литературы}

[1] Вавилов В.С., Челядинский А.Р. // УФН. 1995. Т. 165. № 3. C. 348.

[2] Нусупов К.Х., Бейсенханов Н.Б., Жариков С.К., Бейсембетов И.К., Кенжалиев Б.К., Ахметов Т.К., Сейтов Б.Ж. // ФТТ. 2014. Т. 65. № 11. С. 2231.
[3] Баязитов Р.М., Хайбуллин И.Б., Баталов Р.И., Нурутдинов Р.М. // ЖТФ. 2003. Т. 63. № 6. С. 82.

[4] Горелик В.С., Сущинский М.М, Хашимов Р.Н. // Труды ФИАН. 1987. Т. 180. С. 127.

[5] Маслова Н.Е., Антоновский А.А., Жигунов Д.М., Тимошенко В.Ю., Глебов В.Н., Семиногов В.Н. // ФТП. 2010. T. 44. № 8. C. 1074.

[6] Емельянов А.В., Казанский А.Г., Кашкаров П.К., Коньков О.И., Теруков Е.И., Фори П.А., Хенкин М.В., Кукин A.B., Beresna M., Kazansky P. //ФТП. 2012. Т. 46. № 6. C. 769.

[7] Володин В.А., Сачков В.А. // ЖЭТФ. 2013. Т. 143. № 1. C.100.

[8] Иго А.В. // Опт. и спектр. 2016. Т. 120. № 4. С. 556.

[9] Мотm Н., Дэвис Э. Электронные процессы в некристаллических веществах. М.: Мир, 1974. 472 с.

[10] Артамонов В.В., Валах М.Я, Киршт Ф., Клюй Н.И., Литовченко В.Г., Нечипорук Б.Д., Романюк Б.Н. // ФТП. 1991. T. 25. № 10. C. 1704

[11] Bracht H., Haller E.E. // Phys. Rev. Lett. 1999. V. 81. N 2. P. 393.

[12] Cody G.D., Tiedje T., Abeles B., Brooks B., Goldstein Y. // Phys. Rev. Lett. 1981. V. 47. N 20. P. 1480.

[13] Arora A.K., Rajalakshmi M., Ravindran T.R., Sivasubramanian V.J. // J. Raman Spectrosc. 2007. V. 38. P. 604.

[14] Faraci G., Gibelisco S., Russo P., Pennisi A.R., Rosa S.L. // Phys. Rev. B. 2006. V. 73. P. 033307.

[15] Igo A.V. // Наносистемы: физика, химия, математика. 2018. T. 9. № 1. C. 132.

[16] Zhigunov D.M., Kamaev G.N., Kashkarov P.K., Volodin V.A. // Appl. Phys. Lett. 2018. V. 113. P. 023101. 